\title{
RELIABILITY OF HEAT SINK OPTIMIZATION USING ENTROPY GENERATION MINIMIZATION
}

\author{
Takahiro Furukawa, Graduate Student, Department of Mechanical Engineering \\ and \\ Wen-Jei Yang, Professor, Department of Mechanical Engineering \\ University of Michigan, Ann Arbor, Michigan 48109, U.S.A.
}

\begin{abstract}
$\underline{\text { ABSTRACT }}$
The design and optimization of electronics cooling systems is not easily accomplished through conventional analysis tools such as analytical and numerical methods. The enhancement in thermal performance causes a rise in pressure drop, which increases the load of pumping power. Consequently, the overall assessment of cooling system requires a trade-off between thermal performance and pressure drop. Entropy generation minimization (EGM) method is based on the theory that a thermodynamically optimized system is the least irreversible, or minimum entropy generation in the system. EGM method has been used as an optimization tool in thermodynamic systems for a broad range of engineering fields, but its reliability and accuracy has not been investigated. In this study, the fin pitch of a plate fin heat sink in free convection environment was optimized by EGM method. Results were compared with both analytical and numerical optimization results. The EGM method predicted slightly higher fin pitch than the analytical and CFD methods but with the same trend. The discrepancy between the analytical and EGM method was within $7-12 \%$, while that between the CFD and EGM method was 5-9\%. With this small discrepancy, it was concluded that the EGM method was very reliable to be used in the fin pitch optimization of the plate fin heat sink subject to free convection.
\end{abstract}

\section{NOMENCLATURE}

$A_{b} \quad=$ heat sink base surface area

$A_{c} \quad=$ cross section area of fin

$C_{p} \quad=$ specific heat of air

$E I \quad=$ Elenbaas number

$g \quad=$ gravity

$H \quad$ = fin height

$h \quad=$ heat transfer coefficient around fin

$k_{a}=$ thermal conductivity of air

$k_{h} \quad=$ thermal conductivity of heat sink

$L \quad=$ fin length

$N \quad=$ total number of fin of heat sink

$P \quad=$ plate-air parameter

$P_{e} \quad=$ perimeter of fin

$p_{f} \quad=$ fin pitch

$q_{b} \quad=$ heat transfer rate to heat sink base $q_{f} \quad=$ heat transfer rate to fin

$R_{h s} \quad=$ overall thermal resistance of heat sink

$R_{\text {fin }}=$ thermal resistance of fin

$\dot{S}_{\text {gen }} \quad=$ entropy generation rate

$\dot{S}_{\text {gen,hs }}=$ entropy generation rate from heat sink

$T_{\infty} \quad=$ ambient temperature

$t_{b} \quad=$ base thickness of heat sink

$t_{f} \quad=$ fin thickness of heat sink

$W \quad=$ heat sink width

$z \quad=$ fin space

$\beta=$ thermal expansion coefficient

$\eta_{f} \quad=$ fin efficiency

$\mu \quad=$ viscosity of air

$\bar{\theta}=$ average temperature difference between heat sink and ambient air

$\theta_{b} \quad=$ temperature difference between heat sink base and ambient air

$\rho \quad=$ density of air

\section{INTRODUCTION}

The method of entropy generation minimization (EGM), introduced by Bejan, ${ }^{1,2}$ is used as an optimization tool of thermodynamic systems in the present study. The theory of EGM states that all real systems suffer their thermodynamic imperfection due to heat transfer, fluid flow and mass transfer irreversibility. Consequently, the entropy generation can be used as a measure of system's departure from reversibility. Based on this theory, minimizing the entropy generation in the system leads to the optimization of the system. The EGM method has been applied to a broad range of engineering fields ${ }^{3,4,5}$ such as heat exchangers and solar power and refrigeration plants.

Recently, Culham and Muzychka ${ }^{6}$ applied the EGM method to optimization of plate fin heat sinks in electronics applications through simultaneous optimization of heat sink design parameters. Dealing with various geometric parameters, heat transfer rate and material properties of heat sinks, the application of multi-parameter optimization is more productive than an analytical approach with empirical equations and 
powerful numerical simulation which cannot simultaneously optimize more than two parameters.

The theory of the EGM method has been extensively applied by previous researchers, but its accuracy remains uncertain. In this study, the fin pitch of a plate fin heat sink in free convection environment is optimized by the EGM method. Results are compared with both analytical and numerical optimization results. Fin width, length and height and heat dissipation are changed in the fin pitch optimization process.

\section{DESIGN PARAMETER}

Fig. 1 shows the design parameters of a plate fin heat sink. Fin pitch was optimized for three different parameter combinations as listed in Table 1. The heat sink base thickness, $t_{b}$, and fin thickness, $t_{f}$, are 5 and 2 $\mathrm{mm}$, respectively. The gravity direction is along the heat sink channel as shown in Fig. 1. The ambient temperature around heat sink and thermal conductivity of heat sink material, $k_{h}$, is set to be $25^{\circ} \mathrm{C}$ and $200 \mathrm{~W} / \mathrm{mK}$, respectively.

Table 1 Heat sink design parameter combinations

\begin{tabular}{|l|c|c|c|}
\hline Parameter set & 1 & 2 & 3 \\
\hline Heat dissipation [W] & 5 & 10 & 20 \\
\hline Heat sink width [cm] & 5 & 10 & 10 \\
\hline Fin length [cm] & 5 & 10 & 10 \\
\hline Fin height [cm] & 1.5 & 3 & 5 \\
\hline
\end{tabular}

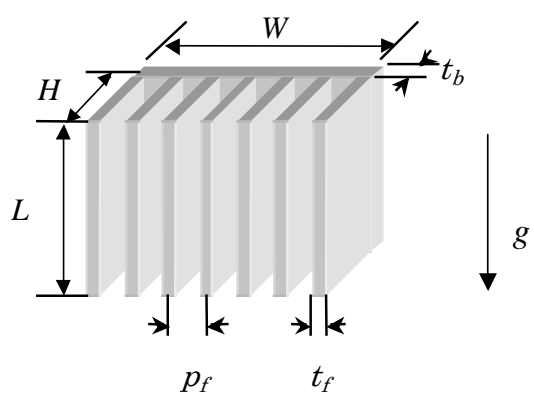

Fig. 1 Design parameters of a plate fin heat sink

\section{MODEL DEVELOPMENT FOR EGM METHOD}

Entropy generation rate for extended surface under free convection were derived by $\mathrm{Bejan}^{2}$ as follows:

$$
\dot{S}_{g e n}=\frac{q_{b} \theta_{b}}{T_{\infty}^{2}}
$$

The temperature difference between the heat sink base and the ambient air, $\theta_{b}$, may be expressed in terms of the overall heat sink resistance, $R_{h s}$, as

$$
\theta_{b}=q_{b} R_{h s}
$$

Therefore, entropy generation rate from a plate fin heat sink under free convection is rewritten as

$$
\dot{S}_{g e n, h s}=\frac{q_{b}^{2} R_{h s}}{T_{\infty}^{2}}
$$

The overall heat sink resistance, $R_{h s}$, is defined as

$$
\begin{gathered}
R_{h s}=\frac{1}{\frac{N}{R_{f i n}}+h L\left(W-t_{f} N\right)}+\frac{t_{b}}{k L W} \\
N=\frac{W-t_{f}}{p_{f}}+1
\end{gathered}
$$

$N$ is the total number of fin and $R_{f i n}$ is the fin resistance and is defined as ${ }^{7}$

$$
R_{f i n}=\frac{1}{\sqrt{h P_{e} k_{h} A_{c}} \tanh (m H)}
$$

where

$$
\begin{aligned}
& m=\sqrt{\frac{h P_{e}}{k_{h} A_{c}}} \\
& P_{e}=2\left(L+t_{f}\right) \\
& A_{c}=L t_{f}
\end{aligned}
$$

Elenbaas $^{8}$ gives the heat transfer coefficient around the heat sink, $h$, as

$$
h=\frac{k_{a}}{z}\left[\frac{576}{(E I)^{2}}+\frac{2.873}{(E I)^{1 / 2}}\right]^{-1 / 2}
$$

Here, EI is the Elenbaas number defined as

$$
E I=\frac{\rho^{2} \beta g C_{p} z^{4} \bar{\theta}}{\mu k_{a} L}
$$

in which 


$$
z=p_{f}-t_{f}
$$

$\bar{\theta}$ is the average temperature difference between the heat sink and the ambient air, defined as

$$
\bar{\theta}=\overline{T_{h s}-T_{\infty}}
$$

Substituting equations (4) through (13) into Equation (3), One gets the entropy generation rate in terms of geometric parameters, heat generation and base temperature as

$$
\dot{S}_{g e n, h s}=f\left(L, W, H, t_{f}, t_{b}, p_{f}, q_{b}, T_{\infty}, \bar{\theta}\right)
$$

The equation of entropy generation rate (14) can be used to optimize any parameter in a plate fin heat sink.

$$
\dot{S}_{g e n, h s}=f\left(L, W, H, t_{f}, t_{b}, p_{f}, q_{b}, T_{\infty}, \bar{\theta}\right)=f\left(x_{i}\right)
$$

where

$i=1,2, \ldots \ldots, n$ ( $n=$ number of parameters $)$

Using the Newton-Raphson method ${ }^{9}$, the desired parameter is optimized by minimizing the entropy generation rate from the heat sink as,

$$
\frac{\partial \dot{S}_{g e n, h s}}{\partial x_{i}}=0
$$

\section{FIN PITCH OPTIMIZATION OF PLATE FIN HEAT SINK USING EGM METHOD}

As previously mentioned, the entropy generation rate of plate fin heat sink can be written as the function of fin length, fin height, base width, fin thickness, base thickness, fin pitch, heat transfer rate to heat sink and ambient temperature. In electronics cooling applications, an overall heat sink volume size is determined based on the chip size where the heat sink is attached and physically allowable space limit of electronic device. The fin length and height and base width are specified in the early design stage. Fin thickness and base thickness might be fixed in terms of heat spreading resistance of the heat sink material. Fin base should have enough thickness so that heat can spread evenly across the heat sink base. Fin should be thick enough so that heat spreads evenly from the base to fin tip. If the amount of heat generation rate applied to the heat sink base is given, the most important design parameter of the plate fin heat sink is its fin pitch. Therefore, all parameters in the heat sink design except the fin pitch are fixed and the entropy generation minimization method is applied to the fin pitch optimization of the plate fin heat sink.

The temperature difference between the heat sink base and the ambient air, $\theta_{b}$, defined Equation (2), and the fin efficiency $\eta_{f}$ has to be assumed before iteration starts. With the use of a high thermal conductivity material, for heat sink, it is assumed that fin efficiency is 0.99 . The two assumed values must be verified after the iteration converged.

$$
\bar{\theta}=\eta_{f} \theta_{b}
$$

where

$$
\eta_{f}=\frac{\tanh (m H)}{m H}
$$

A code for optimization using method of EGM was written by Mathematica ${ }^{10}$.

For the parameter set 1 in Table 1, the fin pitch and heat sink base temperature are initially assumed to be $4 \mathrm{~mm}$ and $77.2^{\circ} \mathrm{C}$ respectively. The ambient temperature around heat sink is set to be $25^{\circ} \mathrm{C}$. Table 2 shows the result of each iteration until the values converge.

Table 2 Fin pitch optimization using EGM Method

\begin{tabular}{|c|c|c|c|}
\hline Iteration & $\begin{array}{c}\text { Fin } \\
\text { pitch } \\
{[\mathrm{mm}]}\end{array}$ & $\begin{array}{c}\text { Base } \\
\text { temperature } \\
{\left[{ }^{\circ} \mathrm{C}\right]}\end{array}$ & $\begin{array}{c}\text { Entropy } \\
\text { generation } \\
\text { rate }[\mathrm{W} / \mathrm{K}]\end{array}$ \\
\hline 0 & 4.00 & ------- & 3.0322 \\
\hline 1 & 4.54 & 441.4 & 1.6477 \\
\hline 2 & 5.23 & 253.0 & 0.9302 \\
\hline 3 & 6.05 & 153.7 & 0.5904 \\
\hline 4 & 6.88 & 105.6 & 0.4623 \\
\hline 5 & 7.58 & 86.50 & 0.4268 \\
\hline 6 & 8.03 & 80.30 & 0.4204 \\
\hline 7 & 8.18 & 78.00 & 0.4199 \\
\hline 8 & 8.20 & 77.34 & 0.4199 \\
\hline 9 & 8.20 & 77.27 & 0.4199 \\
\hline
\end{tabular}

After 9 iterations, one obtains the optimized fin pitch of $8.20 \mathrm{~mm}$ when the base temperature is converged to $77.27^{\circ} \mathrm{C}$, which agrees well with the initially assumed base temperature of $77.2^{\circ} \mathrm{C}$. Therefore, the optimized fin pitch of $8.20 \mathrm{~mm}$ is reliable number. Entropy generation rate from a heat sink decrease and converge and Fig. 2 shows the entropy generation rate from a heat sink with respect to its fin pitch for the parameter set 1 . As can be seen from the 
figure, the entropy generation rate is minimized at the optimized fin pitch of $8.20 \mathrm{~mm}$. Similarly for the other parameter sets, fin pitches were optimized with the results listed in Table 3 .

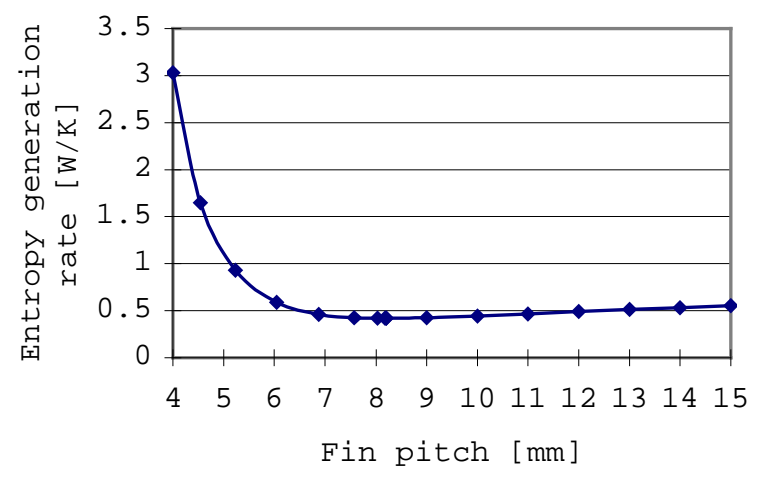

Fig. 2 Entropy generation rate from heat sink with respect to its fin pitch, for parameter set 1

Table3 Fin pitch optimization results

\begin{tabular}{|l|c|c|c|}
\hline Parameter set & 1 & 2 & 3 \\
\hline Optimized fin pitch [mm] & 8.20 & 10.30 & 9.89 \\
\hline
\end{tabular}

\section{OPTIMIZATION USING ANALYTICAL METHOD}

The analytical method used for fin pitch optimization was introduced by Kraus and Bar-Cohen ${ }^{11}$, based on the earlier work of Elenbaas ${ }^{8}$. The procedure is demonstrated below for the parameter set 1 .

First, the average fin temperature is assumed to be $80^{\circ} \mathrm{C}$ with the average air temperature around the fin as $52.5^{\circ} \mathrm{C}$. The temperature difference between the fin base and ambient air, $\theta_{b}$, is $55^{\circ} \mathrm{C}$. Thermal properties of air at $52.5^{\circ} \mathrm{C}$ are used in calculations.

Similarly, with the use of a high thermal conductivity material, for heat sink, the assumed fin efficiency of $\eta_{f}=0.99$, yields the average temperature difference between the fin surface and ambient air of

$$
\bar{\theta}=\eta_{f} \theta_{b}=0.99 * 55=54.45^{\circ} \mathrm{C}
$$

This fin efficiency will be later verified by the result of the optimization process.

Bar-Cohen and Rohsenow ${ }^{12}$ give for the optimum fin spacing, $z_{\text {opt }}$ as

$$
z_{\text {opt }}=2.714 P
$$

Here $P$ is called plate-air parameter, with the thermal properties of the air evaluated at the average temperature between the plate and the ambient air, defined as

$$
P=\left(\frac{\mu k_{a} L}{C_{p} \rho^{2} g \beta \bar{\theta}}\right)^{1 / 4}[\mathrm{~m}]
$$

Computation yields $P$ and $z_{o p t}$ for this plate fin as

$$
P=1.948[\mathrm{~mm}] \text { and } z_{\text {opt }}=5.287[\mathrm{~mm}]
$$

respectively. Therefore, the optimum fin pitch, $p_{f, o p t}$ is

$$
p_{f, o p t}=7.287[\mathrm{~mm}]
$$

This optimized fin pitch gives the total number of fins, $N$

$$
N=\frac{W}{p_{f, o p t}}+1=7.862 \approx 8
$$

With the use of 8 fins, the designed fin space $z$ and $p_{f}$ are obtained

$$
z=4.857[\mathrm{~mm}] \text { and } p_{f}=0.006857[\mathrm{~mm}] \text {, }
$$

respectively. Equation (10) yields the heat transfer coefficient for natural convection between vertical isothermal plates as

$$
h=6.296\left[\mathrm{~W} / \mathrm{m}^{2}-\mathrm{K}\right]
$$

For a fin with negligible heat transfer from the tip, in other words for an adiabatic fin tip, the fin heat transfer rate $q_{f}$ can be expressed as ${ }^{4}$

$$
q_{f}=M \tanh (m H)
$$

where,

$$
M=\sqrt{h P_{e} k_{h} A_{c}} \theta_{b} \text { and } m=\sqrt{h P_{e} / k_{h} A_{c}}
$$

$P_{e}$ is fin perimeter and $A_{c}$ is fin cross sectional area.

Thus, one finds

$$
q_{f}=0.539[\mathrm{~W}]
$$

With the heat transfer coefficient around fins known, the total heat dissipation from the plate fin with the base surface area $A_{b}$ is found to be 


$$
Q=N q_{f}+h A_{b} \theta_{b}=4.899[\mathrm{~W}]
$$

The fin efficiency is already defined by Equation (18). It gives the fin efficiency of

$$
\eta_{f}=0.998 \cong 0.99
$$

which agrees with the assumed value. Similarly the same optimization is conducted for the parameter set 2 and 3.

\section{OPTIMIZATION USING CFD SOFTWARE}

The fin pitch of plate heat sink can be optimized using a computational fluid dynamics software called, Flotherm, whose numerical scheme is based on the finite volume method. This software has been used in the electronics cooling design. The optimization procedure is demonstrated below for the parameter set 1. Fig. 3 shows the simulation model for this plate heat sink. Since the arrays of straight plate fins are symmetric, it is sufficient to perform the computational simulation for only one portion of the arrays of fins. Let the number of fins of this model be seven and the fin pitch $p_{f}$ be $8 \mathrm{~mm}$. For the total heat transfer rate to the heat sink base, $q_{b}$, of $5 \mathrm{~W}$, the fraction of heat input, $q_{p}$, attached in the fin base in this simulation is

$$
q_{p}=q_{b} \frac{p_{f} / 2}{W}=0.4[\mathrm{~W}]
$$

Let the direction of gravity be in the negative $y$ direction. Results are obtained in Fig. 4 for the velocity distribution and Fig. 5 for the temperature distribution of the plate fin heat sink.

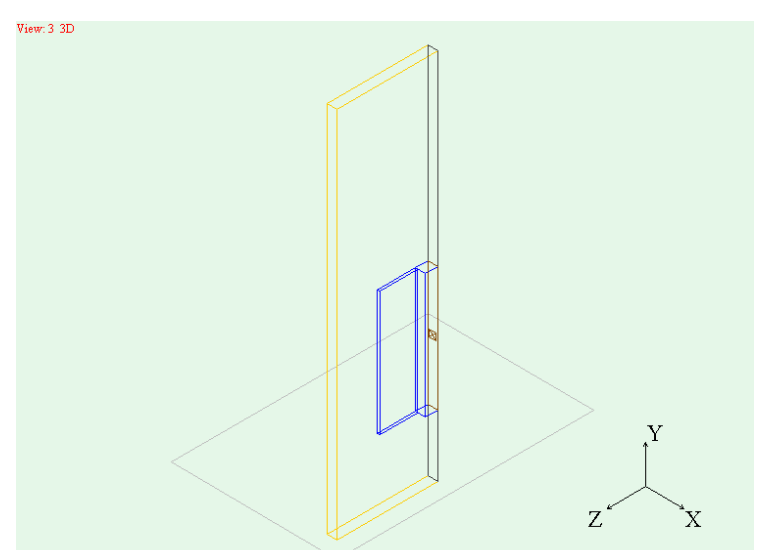

Fig. 3 Flotherm simulation model of a portion of heat sink

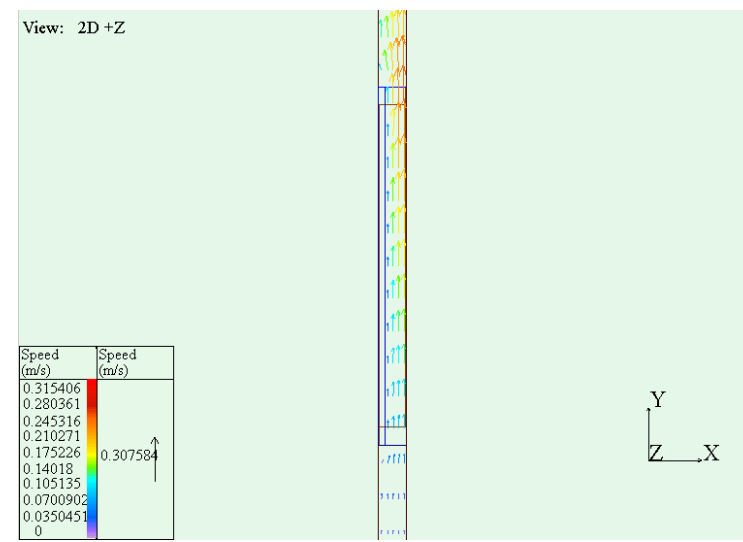

Fig. 4 Velocity distribution in channel between fins

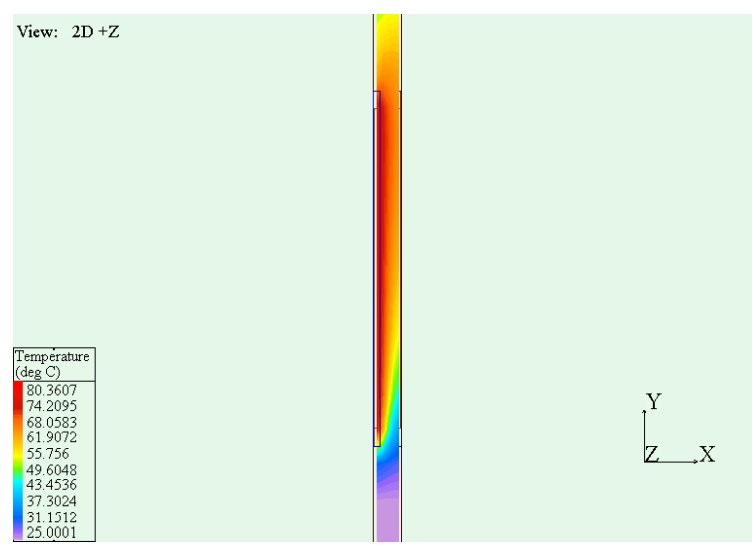

Fig. 5 Temperature distribution in channel between fins

Simulations were repeated for the number of fin $N=$ 5 to 11 . Results are listed in Table 4 while Fig. 6 shows the fin base temperature vs. fin pitch. An inspection of Table 4 and Figure 6 reveals the optimized fin pitch to be $7-8 \mathrm{~mm}$ and the optimized number of fin of 7 or 8 .

Table 4 Simulation result of plate fin heat sink

\begin{tabular}{|c|c|c|}
\hline Number of fin & $\begin{array}{c}\text { Fin pitch } \\
{[\mathrm{mm}]}\end{array}$ & $\begin{array}{c}\text { Base temperature } \\
{\left[{ }^{\circ} \mathrm{C}\right]}\end{array}$ \\
\hline 11 & 4.80 & 93.87 \\
\hline 10 & 5.33 & 87.68 \\
\hline 9 & 6.00 & 83.00 \\
\hline 8 & 6.86 & 80.66 \\
\hline 7 & 8.00 & 80.38 \\
\hline 6 & 9.60 & 83.54 \\
\hline 5 & 12.00 & 88.85 \\
\hline
\end{tabular}




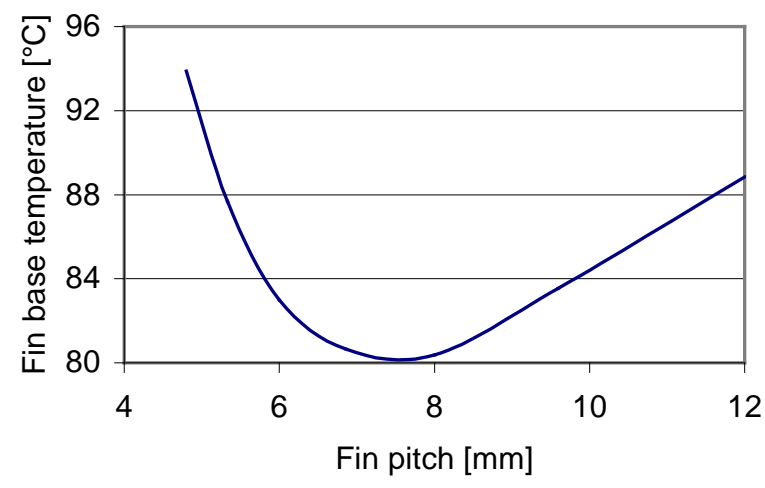

Fig. 6 CFD optimization, fin base temperature vs. fin pitch, for parameter set 1

\section{COMPARISON EGM OPTIMIZATION RESULTS WITH OTHER CONVENTIONAL METHODS}

Fig. 7 compares the results of fin pitch optimized using analytical, CFD and EGM methods. The optimized fin pitch of the EGM method is slightly higher than those of analytical method and CFD, but it shows the same trend with the other optimized fin pitches. The discrepancy between the analytical and EGM method is within 7-12\%, while that between the CFD and EGM method is 5-9\%.

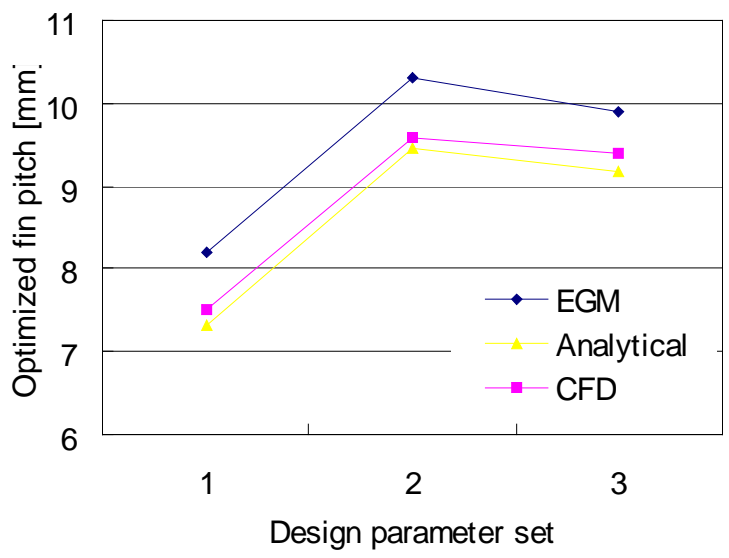

Fig. 7 Optimized fin pitch result, EGM, analytical CFD

\section{CONCLUSIONS}

The EGM method predicted slightly higher fin pitch than the analytical and CFD methods but with the same trend. Even the three methods are based on completely different theory, the maximum discrepancy of $12 \%$ range is small and acceptable. Therefore, the EGM method is very reliable to be used in the fin pitch optimization of the plate fin heat sink subject to free convection.

\section{REFERENCES}

${ }^{1}$ Bejan, A., "Entropy Generation Through Heat and Fluid Flow," John Wiley and Sons Ltd., New York, 1982

${ }^{2}$ Bejan, A., "Entropy Generation Minimization," CRC Press, New York, 1996

${ }^{3}$ Vargas, J. V. C. and Bejan, A., "Thermodynamic Optimization of Finned Crossflow Heat Exchangers for Aircraft Environmental Control Systems," International Journal of Heat and Fluid Flow, Vol. 22, No. 6, 2001, pp. 657-665.

${ }^{4}$ Bejan, A. and Pfister P. A., "Evaluation of Heat Transfer Augmentation Techniques," Letters in Heat and Mass Transfer, Vol. 7, 1980, pp. 97-106.

${ }^{5}$ Krane, R. J., "A Second Law Analysis of the Optimum Design and Operation of Thermal Energy Storage System," International Journal of Heat and Mass Transfer, Vol. 30, 1987, pp. 43-57

${ }^{6}$ Culham, J. R. and Muzychka, Y. S., "Optimization of Plate Fin Heat Sinks Using Entropy Generation Minimization," 2000 Inter Society Conference on Thermal Phenomena, 2000, pp. 8-15

${ }^{7}$ Incropera F. and Dewitt, D., Introduction to Heat Transfer, John Wiley \& Sons, New York, 1996

${ }^{8}$ Elenbaas W., "Heat Distribution of Parallel Plates by Free Convection," Physica, Vol. 9, No. 1, 1942, pp. 665-671.

${ }^{9}$ Stoecker, W., "Design of Thermal Systems," McGraw Hill, New York, 1980, pp. 117-119

${ }^{10}$ Wolfram S., The Mathematica Book Version 4, Cambridge University Press, New York, 1999

${ }^{11}$ Bar-Cohen, A. and Kraus A., "Advances in Thermal Modeling of Electronic Components and Systems," Vol. 4, ASME press, New York, 1998, pp. 251-316.

${ }^{12}$ Bar-Cohen, A. and Rohsenow, W. M., "Thermally Optimum Spacing of Vertical, Natural Convection Cooled, Parallel Plates," J Heat Trans, Vol. 106, 1984, pp. 116-123 